\title{
A STUDY OF ADVERSE EFFECTS PROFILE OF VARIOUS ANTIHYPERTENSIVE DRUGS AMONG HYPERTENSIVE PATIENTS IN A TERTIARY CARE CENTRE
}

\author{
Ujwala P. Gawali1, Komal S. Gawand ${ }^{2}$
}

${ }^{1}$ Associate Professor, Department of Pharmacology, Dr. V.M. GMC, Solapur.

2 Postgraduate Student, Department of Pharmacology, Dr. V.M. GMC, Solapur.

\begin{abstract}
\section{BACKGROUND}

Hypertension is the leading cause of morbidity and mortality worldwide. The aim of hypertensive therapy is to prevent morbidity and mortality associated with persistent raised BP by lowering it to an acceptable level. Antihypertensive drugs are frequently associated with undesirable effects that may limit treatment options and reduce patient adherence to treatment. Because hypertension is an asymptomatic disorder and requires long term therapy, consideration of potential adverse effects of drugs used for its treatment is important for making appropriate choice.
\end{abstract}

Aim of the study was to assess the adverse effect profile of various antihypertensives prescribed at a tertiary care centre.

\section{MATERIALS AND METHODS}

The study was an observational study conducted by face-to-face interview among mild-to-moderate hypertensive patients who received antihypertensive as a monotherapy or combined drug therapy not less than three months, attending medicine outpatient department on a daily basis for a period of 12 months. Study was approved by the institutional ethics committee; informed consent form was obtained from the patients participating in the study.

\section{RESULTS}

Total 2080 patients who were on hypertensives, $40.77 \%$ patients were on monotherapy and $59.23 \%$ patients were on combined drug therapy. Adverse effects were observed among 1003 patients and were more in patients with combination therapy (62.11\%) than patients on monotherapy (37.89\%). Among monotherapy, Enalapril was associated with most adverse effects (17.15\%) as compared to Amlodipine (13.66\%) and Atenolol (7.08\%). Triple therapy (37.09\%) was associated with more adverse effects as compared to dual therapy $(25.02 \%)$.

\section{CONCLUSION}

At a tertiary care centre, enalapril and amlodipine were most commonly prescribed drugs while enalapril was most commonly associated with adverse effects as compared to amlodipine and atenolol. The combination therapy was associated with more adverse effects as compared to monotherapy in the present study. This study setting was institutional based which may not be generalised. However, assessment of adverse effects associated with use of antihypertensive drugs should be done continuously to prevent treatment dropout and improve patient's adherence to treatment.

\section{KEYWORDS}

Adverse Effects, Antihypertensive Drugs, Hypertensive Patients.

HOW TO CITE THIS ARTICLE: Gawali UP, Gawand KS.A study of adverse effects profile of various antihypertensive drugs among hypertensive patients in a tertiary care centre. J. Evolution Med. Dent. Sci. 2016;5(104):7633-7637, DOI:10.14260/Jemds/2016/1723

\section{BACKGROUND}

Hypertension is the leading cause of morbidity and mortality worldwide. The World Health Organization (WHO) report which examined the major risk factors for global disease identified hypertension as one of the most important cause of the disease burden of developed and developing nations. ${ }^{1}$

Blood pressure is expressed by two measurements, the systolic and diastolic pressures which are the maximum and minimum pressures respectively. Normal blood pressure at rest is within the range of 100 to $140 \mathrm{~mm}$ of $\mathrm{Hg}$ systolic and 60 to $100 \mathrm{~mm}$ of $\mathrm{Hg}$ diastolic. ${ }^{2}$ High blood pressure is present if

Financial or Other, Competing Interest: None.

Submission 22-11-2016, Peer Review 14-12-2016,

Acceptance 22-12-2016, Published 29-12-2016.

Corresponding Author:

Ujwala P. Gawali,

Department of Pharmacology

Dr. V. M. GMC, Solapur.

E-mail: ujwalagawali1963@gmail.com

DOI: $10.14260 /$ jemds/2016/1723 the resting blood pressure is persistently at or above $140 / 90$ $\mathrm{mm}$ of $\mathrm{Hg}$ for most adults. ${ }^{3}$ The epidemiological studies of last 20 years show that prevalence of hypertension in urban location has stabilised to about $20-30 \%$ but it has increased in rural population from 15 to $25 \%{ }^{4}$ Residual lifetime risk for developing hypertension in middle-aged and elderly individuals is $90 \%$, indicating a huge public health burden. 5 The aim of hypertensive therapy is to prevent morbidity and mortality associated with persistent raised BP by lowering it to an acceptable level with minimum inconvenience to the patient. Compared with other known risk factors for acute myocardial infarction, heart failure, stroke, end-stage renal disease, hypertension is perhaps the simplest to diagnose, easiest to treat and one of the most cost effective preventive strategies. ${ }^{6}$ For the treatment of hypertension, a broad range of antihypertensive medications are currently available. Evidence suggests that reduction of the blood pressure by 5 mmHg can decrease the risk of stroke by $34 \%$, of ischaemic heart disease by $21 \%$, and reduce the likelihood of dementia, heart failure and mortality from cardiovascular disease. ${ }^{7}$ 
Antihypertensive drugs are frequently associated with undesirable effects that may limit treatment options and reduce patient adherence, which may hinder blood pressure control. It is thought that different discontinuation rates for various classes of antihypertensives are probably related to their different rates of adverse symptoms. Because hypertension is an asymptomatic disorder and requires longterm therapy, 8 consideration of potential undesirable effects of drugs used for its treatment is important for making appropriate choice. In this context, precise understanding of efficacy and adverse effect profile of different antihypertensive drugs is essential. Monitoring of adverse effects of drug is more important in case of chronic ailments such as hypertension. A good control of blood pressure and avoidance of adverse effect can, however, be achieved by appropriate drug selection and dosage, carried out after careful consideration of known adverse effect profile of different compounds in reducing blood pressure.

Amlodipine, atenolol and enalapril are commonly prescribed antihypertensives in our tertiary care centre. Calcium channel antagonists enjoy a reputation of efficacy and tolerability. They can be used in patients with diabetes mellitus, hyperlipidaemia, coronary artery disease, asthma, gout. Amlodipine is a long-acting dihydropyridine calcium antagonist indicated for both hypertension and angina. Unlike older short-acting dihydropyridines, it is safe in patients with heart disease. ${ }^{9}$ The most common side effects caused by this class of drug, particularly the dihydropyridines, are due to excessive vasodilation. Symptoms include dizziness, hypotension, headache, flushing, digital dysaesthesia, and nausea. Patients also may experience constipation, peripheral oedema, coughing, wheezing, and pulmonary oedema. ${ }^{10}$ Beta blockers have been widely used in the treatment of hypertension. However, this class of drug is contraindicated in patients with asthma, bradyarrhythmias and peripheral vascular disease. Atenolol is beta-adrenergic blocking agent that has shown to be effective given once daily as monotherapy in treatment of hypertension. ${ }^{11}$ Adverse effects associated with the use of beta blockers include: nausea, diarrhoea, bronchospasm, dyspnoea, cold extremities, bradycardia, hypotension, heart failure, heart block, fatigue, dizziness, abnormal vision, decreased concentration, hallucinations, insomnia, nightmares, clinical depression, sexual dysfunction, erectile dysfunction and/or alteration of glucose and lipid metabolism. ${ }^{10}$ Enalapril is an angiotensin converting enzyme inhibitor which is used in hypertension as once daily dose of 5 mg titrated upwards up to $40 \mathrm{mg}$. ${ }^{12}$ Side effects common to all ACE inhibitors include acute renal failure, hyperkalaemia, dry cough sometimes accompanied by wheezing, and angioedema. Minor toxic effects seen more typically include altered sense of taste, allergic skin rashes, and drug fever, which may occur in as many as $10 \%$ of patients. 10

The result of adverse effect profile would provide the necessary information on adverse effects of different antihypertensive medications. So the objective of this study was to evaluate the incidence of adverse effects in patients receiving antihypertensive drugs at the tertiary care centre.

\section{MATERIALS AND METHODS}

The study was an observational study, conducted by face-toface interview among mild-to-moderate hypertensive patients who received antihypertensive medicines not less than three months, attending medicine outpatient department on a daily basis in a tertiary care centre for a period of 12 months. Study was approved by the institutional ethics committee, informed consent form was obtained from the patients participating in the study. The aim of the study was to assess adverse effect profile of various antihypertensives prescribed at the tertiary care centre as a monotherapy or combined drug therapy. All patients taking other than antihypertensive medication, patients having other comorbid conditions like IHD, heart failure, COPD, diabetic mellitus, peripheral vascular disease, cardiomyopathy \& mentally compromised or unconscious patients and patients unable to respond to verbal questions were excluded from the study. They were asked about adverse effects which they felt after taking medication. The data collected through questionnaire was organised, tabulated, results were calculated on basis of Microsoft Excel and analysed by using statistics such as percentage, mean, standard deviation, etc.

\section{RESULTS}

Of total 2080 hypertensive patients, 1224 (58.85\%) were males and 856 (41.15\%) were females (FIG.1). Out of 2080 patients, $848(40.77 \%)$ patients were on monotherapy and $1232(59.23 \%)$ patients were on combined drug therapy (FIG.2). Adverse effects were observed among 1003 (48.22\%) patients, among which females $514(24.71 \%)$ were more as compared to males 489 (23.50\%). The most vulnerable age group with maximum adverse effects was 41-60 years. (Table 1)

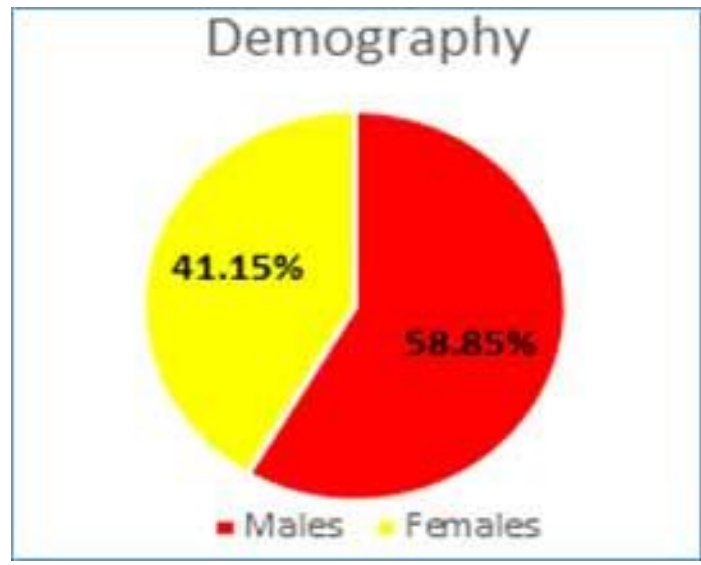

Figure 1

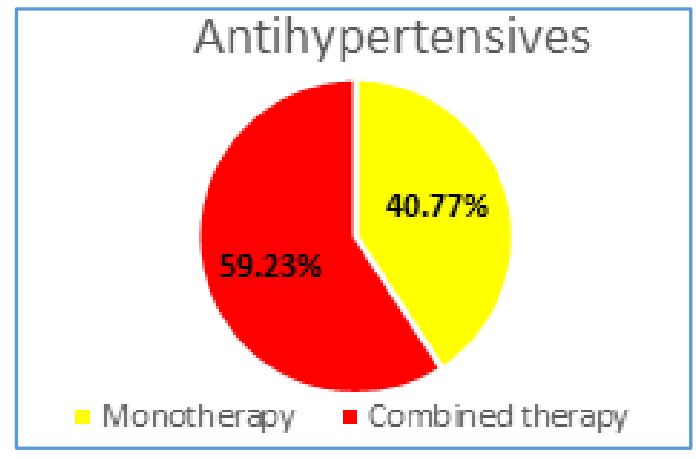

Figure 2

Among monotherapy, ACE inhibitor Enalapril ( $n=350)$ and Ca channel blocker Amlodipine $(n=332)$ were the most prescribed drug followed by beta blocker Atenolol ( $n=166)$. Among combined drug therapy, only two combinations were 
prescribed, dual therapy of Amlodipine with Atenolol and triple drug therapy of Amlodipine, Atenolol and Enalapril. Most of the patients were on triple therapy $(n=704)$ than on dual therapy ( $n=528)$. Adverse effects were observed more in patients with combination therapy 623 (62.11\%) than patients on monotherapy 380 (37.89\%). Among monotherapy, Enalapril was associated with most adverse effects (17.15\%) as compared to Amlodipine (13.66\%) and Atenolol (7.08\%). Triple therapy $(37.09 \%)$ was associated with more adverse effects as compared to dual therapy (25.02\%).
Among monotherapy, the only adverse effect observed with Enalapril was dry cough $(\mathrm{n}=172)$, while peripheral oedema $(n=69)$ was most common adverse effect among patients on amlodipine. Dizziness and headache were adverse effects observed in patients on atenolol therapy and on dual therapy of amlodipine and atenolol. Dry cough, dizziness and constipation were more common adverse effects in patients on triple therapy of amlodipine, atenolol and enalapril. (Table 2).

\begin{tabular}{|c|c|c|c|c|c|}
\hline & \multicolumn{2}{|c|}{ Patients with Adverse Effects } & \multicolumn{2}{|c|}{ Patients without Adverse Effects } & \multirow[t]{2}{*}{ Total } \\
\hline Age & Male & Female & Male & Female & \\
\hline$<20$ & 5 & 4 & 10 & 12 & 31 \\
\hline $21-30$ & 10 & 20 & 34 & 14 & 78 \\
\hline $31-40$ & 128 & 130 & 215 & 70 & 543 \\
\hline $41-50$ & 178 & 192 & 242 & 136 & 748 \\
\hline $51-60$ & 116 & 132 & 162 & 66 & 476 \\
\hline 61-70 & 48 & 34 & 57 & 40 & 179 \\
\hline$>70$ & 4 & 2 & 15 & 4 & 25 \\
\hline Total & 489 & 514 & 735 & 342 & 2080 \\
\hline \multicolumn{6}{|c|}{ Table 1} \\
\hline
\end{tabular}

\begin{tabular}{|c|c|c|c|c|c|}
\hline Adverse Effects & $\begin{array}{c}\text { Enalapril } \\
(n=350)\end{array}$ & $\begin{array}{c}\text { Amlodipine } \\
(n=332)\end{array}$ & $\begin{array}{l}\text { Atenolol } \\
(\mathrm{n}=166)\end{array}$ & $\begin{array}{c}\text { Amlodipine +Atenolol } \\
(n=528)\end{array}$ & $\begin{array}{c}\text { Amlodipine +Atenolol +Enalapril } \\
(n=704)\end{array}$ \\
\hline Peripheral oedema & & 69 & & 10 & 13 \\
\hline Dry cough & 172 & & 06 & 30 & 113 \\
\hline Flushing & & 11 & & & \\
\hline Headache & & 14 & 23 & 56 & 22 \\
\hline Dizziness & & 10 & 24 & 120 & 138 \\
\hline Palpitations & & 05 & & 05 & 10 \\
\hline Dyspnoea & & 04 & & & \\
\hline Insomnia & & 05 & 18 & 20 & 20 \\
\hline Abdominal pain & & 19 & & 10 & 05 \\
\hline Constipation & & & & & 51 \\
\hline No Adverse effects & 178 & 195 & 95 & 277 & 332 \\
\hline
\end{tabular}

\section{DISCUSSION}

The overall occurrence of hypertension is similar between both men and women, but differs with age. ${ }^{13}$ For those younger than 45 years old, high blood pressure is more common in men than women. For those 65 years old or above, high blood pressure affects women more than men. ${ }^{14,15}$ BP values increase with age, and HTN is very common with the elderly. The lifetime risk of developing HTN among those 55 years of age and older who currently have normal BP is $90 \%{ }^{13,14}$ For the majority of patients with high blood pressure, the cause is unknown. This is classified as primary or essential HTN. A small portion of patients have a specific cause of their high blood pressure, which is classified as secondary HTN.13,15,16 Treatment for hypertensive patients includes both nonpharmacologic (lifestyle changes) and pharmacologic (medication) therapy to lower blood pressure and prevent cardiovascular (heart) events such as a heart attack. Implementation of lifestyle interventions should be used throughout the management of all patients with high blood pressure.13,14 According to the updated 2014 Eighth Joint National Committee (JNC-8) guidelines on HTN, evidence from clinical trials indicate that antihypertensive medications should be initiated in patients less than 60 years old if the systolic blood pressure is persistently $>140 \mathrm{mmHg}$ and the diastolic blood pressure is persistently $>90 \mathrm{mmHg}$ despite non-pharmacologic therapy. If the patient's age is 60 or above, antihypertensive therapy should be initiated if the systolic blood pressure is $>150 \mathrm{mmHg}$ and the diastolic blood pressure is $>90 \mathrm{mmHg} .17,18$

About $35 \%$ of hypertensive patients will discontinue their medication within six months, ${ }^{19}$ and in at least $50 \%$ of cases, the reason for discontinuation relates to adverse effects and patient dissatisfaction. ${ }^{20}$ Therefore, it is imperative that hypertension practitioners are fully cognisant of the adverse effects of antihypertensive drugs. Therefore, a study on adverse effects of antihypertensive drugs was undertaken.

The demographic details of our study population showed predominance of adverse effects in females over males, which was similar to that reported in other studies found in the literature. ${ }^{21,22}$

In this study, ACE inhibitor or Calcium channel blocker is the most commonly prescribed antihypertensive drug as monotherapy. According to a study conducted by Nelson C, 23 ACE inhibitors and calcium channel blockers are consistently the most frequently prescribed antihypertensive agents in both younger and older patients with hypertension. It was seen that combined drug therapy was associated with more 
adverse effects than monotherapy which was similar to previous studies. ${ }^{21,22,24}$ The side effect of dry cough seen with few patients of atenolol and amlodipine combinations is mostly due to atenolol, a selective blocker as demonstrated in the study by Baker 25 that many commercially available selective beta-1 blockers have high affinity for beta-2 receptors. Therefore, both selective and nonselective betablockers may cause bronchoconstriction, which can lead some patients to experience a cough reflex. According to this study, occurrence of adverse effect is more common in patients on ACE inhibitor Enalapril than other antihypertensive medications. This result is similar to the study of Gryglas P 26 and Shrestha et al $^{27}$ in which more side effects were experienced in Enalapril group than that of Amlodipine. The adverse effect mostly associated with enalapril was dry cough. This is in confirmation of previous reports with almost $44 \%$ of patients experiencing dry cough on using ACE inhibitors. ${ }^{28,29} \mathrm{~A}$ dry cough, possibly the result of accumulation of bradykinin in the bronchial mucosa, is the commonest persistent adverse effect. The most common adverse effect seen with amlodipine was peripheral oedema $(n=69)$. Oedema occurs with Ca channel blockers because of vasodilatation in distal arterioles, thereby leading to increased intravascular capillary pressures and increased venous pressures, at least in lower extremities and leakage of fluid into extracellular space. Excessive vasodilatation results in headache, dizziness and flushing.

Present study was a single institutional based so results may not be extrapolated to general population.

\section{CONCLUSION}

At our tertiary care centre, enalapril and amlodipine were the most commonly prescribed drugs while enalapril was most commonly associated with adverse effects as compared to amlodipine and atenolol. The combination therapy was associated with more adverse effects as compared to monotherapy in the present study. This study setting was institutional based which may not be generalised. However, assessment of adverse effects associated with use of antihypertensive drugs should be done continuously to prevent dropout of treatment and improve patient's adherence to treatment.

\section{REFERENCES}

1. Ezzati M, Lopez AD, Rodgers A, et al. Selected major risk factors and global and regional burden of disease. Lancet 2002;360(9343):1347-60.

2. Mancia G, Fagard R, Narkiewicz K, et al. 2013 ESH/ESC guidelines for the management of arterial hypertension. European Heart Journal 2013;34(28):2159-219.

3. Poulter NR, Prabhakaran D, Caulfield M. Hypertension. Lancet (London, England) 2015;386(9995):812-22.

4. Gupta R. Convergence in urban-rural prevalence of HTN in India. J Hum Hypertension 2016;30(2):79-82.

5. Vasan RS, Beiser A, Seshadri S, et al. Residual lifetime risk for developing hypertension in middle-aged women and men: the Framingham heart study. JAMA 2002;287(8):1003-10.

6. Elliott WJ. Hypertension. In: Rakel RE, Bope ET. Conn's current therapy. Saunders, Pennsylvania 2004:363-79.

7. Law M, Wald N, Morris J. Lowering blood pressure to prevent myocardial infarction and stroke: a new preventive strategy. Health Technol Assess 2003;7(31):194.

8. Uppsala Monitoring Centre. The use of the World Health Organization-Uppsala Monitoring Centre (WHO-UMC) system for standardized case causality assessment 2006 Available from: http://whoumc.org/graphics/4409.pdf. last assessed 04-08-2016.

9. Wilson TW, Lacourciere Y, Barnes CC. The antihypertensive efficacy of losartan and amlodipine assessed with office and ambulatory blood pressure monitoring. CMAJ 1998;159(5):469-76.

10. Joshi VD, Dahake AP, Suthar AP. Adverse effects associated with the use of antihypertensive drugs: an overview. International Journal of Pharm Tech Research 2010;2(1):10-3.

11. Dahlof B, Keller SE, Makris L, et al. Efficacy and tolerability of losartan potassium and atenolol in patients with mild to moderate essential hypertension. American J of Hypertension 1995;8(6):578-83.

12. Todd PA, Heel RC. Enalapril: a review of its pharmacodynamics and pharmacokinetic properties and therapeutic use in hypertension and congestive heart failure. Drugs 1986;31(3):198-248.

13. Saseen JJ, MacLaughlin. Hypetension. Chapter 3. In: DiPiro JT, Talbert RL, Yee GC, et al. (edts.) Pharmacotherapy: a pathophysiologic approach. $9^{\text {th }}$ ed. New York: McGraw-Hill Medical 2014.

14. CDC: high blood pressure. Centers for disease control and prevention, 2015. Updated Oct 29, 2014. Cited July 26, 2016. Available from: http://www.cdc.gov/bloodpressure/index.htm

15. Mayo Clinic: high blood pressure (HTN). Mayo Foundation for Medical Education and Research: c2001-2015. Updated Sept 5, 2014. Cited July 26, 2016. About 6 screens. Available from:

http://www.mayoclinic.org/diseases-conditions/highbloodpressure/basics/definition/con-20019580

16. Saseen J. Essential hypertension. Chapter 14. In: Alldredge BK, Corelli RL, Ernst ME, et al. (edts.) Koda-Kimble and Young's Applied Therapeutics: The Clinical Use of Drugs. $10^{\text {th }}$ ed. Philadelphia: Lippincott Williams \& Wilkins 2013.

17. James PA, Oparil S, Carter BL, et al. 2014 evidence based guideline for the management of high blood pressure in adults: report from the panel members appointed to the eighth joint national committee (JNC 8). JAMA 2014;311(5):507-20.

18. Basile J, Bloch MJ. Overview of hypertension in adults. Up To Date. Philadelphia: Wolters Kluwer Health. Updated 2015, Cited July, 2016. Available from:

http://www.uptodate.com/contents/overview-ofhypertension HTN- inadults? source $=$ search_ result\& search=hypertension HTN \&selectedTitle=1\%7E150\#H28

19. Vrijens B, Vincze G, Kristanto $P$, et al. Adherence to prescribed antihypertensive drug treatments: longitudinal study of electronically compiled dosing histories. BMJ 2008;336(7653):1114-7.

20. Bloom BS. Continuation of initial antihypertensive medication after 1 year of therapy. Clin Ther 1998;20(4):671-81. 
21. Kumar VR, Ram VR, Prasad BG, et al. A study of adverse drug reactions due to antihypertensive drugs in a tertiary care teaching hospital. International Journal of Pharmacy and Life Sciences 2011;2(5):767-72.

22. Khurshid F, Aqil M, Alam MS, et al. Monitoring of adverse drug reactions associated with antihypertensive medicines at a university teaching hospital in New Delhi. DARU Journal of Pharmaceutical Sciences 2012;20(1):34.

23. Nelson CR, Knapp DA. Trends in antihypertensive drug therapy of ambulatory patients by US office based physicians. Hypertension 2000;36(4):600-3.

24. Olsen H, Klemetsrud T, Stokke HP, et al. Adverse drug reactions in current antihypertensive therapy: a general practice survey of 2586 patients in Norway. Blood Press 1999;8(2):94-101.

25. Baker JG. The selectivity of beta-adrenoceptor antagonists at the human beta1, beta2 and beta3 adrenoceptors. Br J Pharmacol 2005;144(3):317-22.
26. Gryglas P. The comparison of hypotensive efficiency and tolerability of amlodipine and enalapril in patients with essential hypertension. Pol Arch Med Wewn 2001;105(2):109-15.

27. Shrestha RK, Khan GM, Thapa P, et al. Study of the side effects profile of different antihypertensive drugs among the hypertensive patient. Nepalese Heart Journal 2012;9(1):25-9.

28. Basak SC, Ravi K, Manavalan R, et al. A study of adverse drug reactions to antihypertensive drugs perceived by patients in a rural hospital. Ind J Pham Sci 2004;66(6):814-8.

29. Woo KS, Nicholls MG. High prevalence of persistent cough with angiotensin converting enzyme inhibitors in Chinese. Br J Clin Pharmacol 1995;40(2):141-4. 